Institute for Research on Poverty

Discussion Paper no. 1139-97

\title{
Tax Rates and Work Incentives in the Social Security Disability Insurance Program: Current Law and Alternative Reforms
}

\author{
Hilary Williamson Hoynes \\ Department of Economics \\ University of California, Berkeley \\ E-mail address: hilary@econ.berkeley.edu \\ Robert Moffitt \\ Department of Economics \\ Johns Hopkins University
}

August 1997

The authors would like to thank Gary Painter for excellent research assistance and John Bound, Richard Burkhauser, David Stapleton, Finis Welch, and Irvin Rutman for comments. Financial support was received from the National Institute on Aging.

IRP publications (discussion papers, special reports, and the newsletter Focus) are now available electronically. The IRP Web Site can be accessed at the following address: http://www.ssc.wisc.edu/irp/ 


\begin{abstract}
The Social Security Disability Insurance (SSDI) Program has long been criticized by economists for its apparent work disincentives stemming from the imposition of 100 percent tax rates on earnings. However, the program has been modified in recent years to allow recipients to keep some of their earnings for fixed periods of time. Moreover, additional proposals have been made for lowering the tax rate further and for providing various additional financial work incentives. We use the basic labor supply model to show the expected effect of these reforms on work effort. In addition, we provide a numerical simulation that shows the magnitude of the monetary incentives provided by the reforms for different categories of individuals. We find that the proposed reforms have ambiguous effects on work effort and could, contrary to perceived wisdom, possibly reduce work effort and increase the number of SSDI recipients. However, the simulations show that reforms based on earnings subsidies for private employers are more likely to increase work effort and to lower the caseload.
\end{abstract}




\section{Tax Rates and Work Incentives in the Social Security Disability Insurance Program: Current Law and Alternative Reforms}

\section{INTRODUCTION}

Both academic and policy interest in the disabled and in disability programs in the United States have increased in the last decade. Public support for greater employment of disabled individuals has increased and has resulted in a major piece of legislation, the Americans with Disabilities Act (1990), encouraging employers to accommodate the disabled. At the same time, the caseloads of many disability programs have been growing, most notably that of the Social Security Disability Insurance (SSDI) program. For example, between 1985 and 1995, the number of disabled workers receiving SSDI increased by over 50 percent. The cause of this increase is still only imperfectly understood but it has generated increased interest in the work disincentives of the program. Added to the general societal trend of an increased expectation that recipients of all welfare programs should work, this has led to considerable discussion of methods by which work levels of the disabled and of disability recipients can be increased.

The SSDI program has long been criticized by economists for its work disincentives. The program has traditionally attempted to make a sharp categorical distinction between those who are "disabled" and therefore not expected to work, and those who are "not disabled" and therefore expected to work. But the definition of "disability" is based not only on the presence of a disabling condition but also on the level of earnings itself; for an individual to be deemed "disabled" requires that earnings be below a fixed threshold (called the "substantial gainful activity" amount of earnings, or SGA, currently set at $\$ 500$ per month). Earnings above this threshold are taken to imply the absence of disability and therefore ineligibility for program benefits, thus resulting in a notch in the budget constraint where the tax rate exceeds 100 percent. Since the program was originally introduced, however, the rules have been relaxed to provide some direct financial incentives; these rules allow recipients to work without penalty 
for a fixed period of time (i.e., with a tax rate of zero) and permit a second fixed period of time during which tax rates return to 100 percent but recipient eligibility files are kept "open" to allow the recipient to easily come back onto the rolls should their earnings fall. Those rules are still in place but there continue to be additional proposals for greater reductions in work disincentives, either by further reductions in the tax rate or by other means. For example, in the last year, at least three bills were brought to the floor of the U.S. Congress outlining options for reforming the work incentives of the SSDI program. ${ }^{1}$

In this paper we analyze, both theoretically and empirically, the rules in the current program that attempt to provide work incentives as well as many features of these recently proposed reforms. Theoretically, we show the implications for work effort of each rule or reform suggested by the basic economic model of labor supply. Empirically, we report the results of numerical simulations showing how the budget constraint is affected by each of the reforms- that is, how take-home income would be affected at different levels of hours of work-for different types of individuals. Although we do not provide simulations of actual changes in work effort, which would require information on income and substitution elasticities not available from the literature, our simulations nevertheless show that, surprisingly, the financial incentives implied by some of the reforms are not as strong as expected and may even be in the wrong direction. However, we also provide simulations of the effects of a different type of reform—earnings subsidies—which have quite different, and more favorable, effects.

The outline of the paper is as follows. In Section II, we discuss the rules of the SSDI program governing eligibility and benefits, with a focus on those related to work incentives. We analyze the expected labor supply effects of those rules, and what the existing literature has to say about their magnitudes, in Section III, and also provide numerical simulations of the magnitudes of the financial

\footnotetext{
${ }^{1}$ These bills include the Work Incentive and Self-Sufficiency Act of 1996 (Senator Jeffords), the Rehabilitation and Return to Work Opportunity Act of 1996 (Representative Bunning), and the Transition to Work Act of 1997 (Representative Kennelly).
} 
incentives. In Section IV we discuss the expected effects of various reforms and show their simulated financial incentives. We draw our conclusions in Section V.

\section{ELIGIBILITY AND BENEFITS OF SSDI}

The SSDI (henceforth simply "DI") program is part of the Old Age, Survivors, and Disability Insurance (OASDI), or Social Security, program. Disability benefits were added to the retirement program in 1957 and are designed to provide partial earnings replacement to all workers under 65 who sustain severe, long-term (typically career-ending) disabilities. ${ }^{2}$ All workers covered under Social Security (about 95 percent of the U.S. workforce) are also covered for DI benefits and financing, as the program comes out of employer- and employee-paid FICA taxes. In 1995, the DI program provided benefits for about 4.2 million disabled, non-aged individuals and their families for a total cost of $\$ 40.9$ billion (U.S. House of Representatives 1996).

Throughout the program's history, the determination of an individual's disability status has depended on an assessment of ability to work. Specifically, disability is defined as "the inability to engage in any substantial gainful activity by reason of medically determinable physical or mental impairment which can be expected to result in death or which has lasted or can be expected to last for a continuous period of not less than twelve months" (Social Security Administration 1992). Therefore, a medical definition of disability is not sufficient for benefit receipt. Instead, initial and continuing eligibility is tied to the ability to work. Substantial gainful activity (SGA) is defined as a threshold level of earnings, which is currently set at $\$ 500$ per month. ${ }^{3}$

${ }^{2}$ Other programs for the disabled include the Supplemental Security Income (SSI) program, several veterans' compensation programs, workers' compensation, and state-provided temporary disability benefits.

${ }^{3} \mathrm{SGA}$ is not indexed for price changes and has been increased nine times in the program's thirty-five years. The initial SGA was set at \$100 in 1957, and was $\$ 300$ from 1980 to 1990, before the latest increase to \$500. A deduction is allowed for impairment-related work expenses. 
In addition to meeting the definition of disability, initial eligibility for DI requires having sufficient work history in jobs covered by Social Security. ${ }^{4}$ The DI benefit is equal to 100 percent of the worker's primary insurance amount (PIA), which is a function of the individual's earnings history in Social Security-covered employment. ${ }^{5}$ This benefit can be significant in size, and is typically equal to the full value of the worker's potential Social Security retirement benefit. In 1993, DI benefits for disabled workers averaged $\$ 642$ per month. The PIA calculation is based on a progressive structure under which high-wage workers obtain lower earnings replacement rates than lower-wage workers. The replacement rate in 1994 ranged from 78 percent for workers with low average monthly earnings $(\$ 500)$ to 29 percent among workers with high monthly earnings (\$4500) (U.S. House of Representatives 1994). ${ }^{6}$

Current law allows recipients to pass through up to three different phases of DI receipt. First, there is a 5-month waiting period after disability begins before benefits can be received (although there is no waiting period if the individual returns to the rolls within 5 years of leaving). If the recipient never works thereafter, the subsequent phases are never entered. Second, a trial work period (TWP) allows for up to 9 months of work over a 60 -month calendar period. A month is counted as a trial month (and therefore toward the limit of 9 months) if the individual earns over $\$ 200$ in the month. ${ }^{7}$ During the TWP, benefits are provided in full regardless of the level of earned or unearned income. This phase, introduced in 1960 in order to let recipients test their ability to work without danger of losing benefits, relaxes the strict application of the SGA rule. Third, individuals who accumulate 9 months of work in the TWP have

${ }^{4}$ Applicants must have worked 20 of the last 40 quarters preceding the quarter of application, although the rules differ somewhat for younger workers. The work history required for DI is virtually the same as that required for Social Security retirement benefits.

${ }^{5}$ The benefit can be as much as 150 percent of PIA for disabled workers with families.

${ }^{6}$ The earnings figures refer to the worker's average indexed monthly earnings (AIME) in Social Security employment. The DI benefit, equal to the worker's PIA, is a function of the AIME. Benefits are adjusted for changes in the cost of living. The PIA and AIME are calculated in roughly the same way as they are for Social Security retirement benefits.

${ }^{7}$ The earnings limit was set at $\$ 50$ for much of the history of the program until it was recently increased to $\$ 200$. It is intentionally set at a low level in order to trigger review of recipients who enter work at any level. 
their case reviewed; if the work is judged to be not SGA (generally meaning that it reflects an ability to earn more than the SGA monthly threshold), they are allowed to continue on the rolls as before with the requirement to stay below SGA to retain eligibility. But if the work in which they have been engaged is SGA, benefits are provided in full for a subsequent grace period lasting 3 months, followed by a 36month period called the extended period of eligibility (EPE). ${ }^{8}$ During this period, benefits are provided in full if earnings (net of allowed deductions) are less than SGA, but are reduced to zero if earnings are over SGA. Thus a strict SGA rule is applied, but the recipient's file is kept open and eligibility does not have to be completely reestablished if earnings fall below SGA. This rule is designed to allow recipients who do not succeed in maintaining a steady flow of above-SGA earnings to receive benefit support quickly and easily. After the EPE is exhausted, the individual is dropped from the rolls if he has achieved SGA more or less continually. If the individual has achieved SGA only part of the time, he must file a new application to show that he is still disabled. If he has never achieved SGA (despite having exceeded it during the TWP), the EPE is extended indefinitely but, as soon as he achieves SGA, he is dropped from the rolls. The EPE, which is designed to provide insurance to the recipient should he continue to try to establish himself in the private labor market with steady earnings, was introduced in $1980 .{ }^{9}$

This structure leads to a complicated sequence of marginal tax rates over time. An increase in earnings will increase income but it may be offset by reductions in transfer benefits and other taxes. During the TWP, for example, the marginal tax rate (MTR) is zero, implying that there is no change in benefits in response to a change in earnings or hours. During the EPE, the SGA rule is reintroduced and the MTR is zero for earnings changes below SGA but exceeds 100 percent for earnings increases that

${ }^{8}$ The 3-month grace period is considered part of the 36-month EPE.

${ }^{9}$ Medicare benefits are provided to DI recipients after a 2-year waiting period. Once the individual enters the EPE, Medicare benefits are available for the next 39 months. Thus Medicare is provided for 3 months past the end of the EPE. The availability of Medicare benefits may add substantially to the "insurance" value of DI which is discussed in the text. Once a worker reaches age 65, the DI case is automatically transferred to the Social Security Retirement System. 
exceed SGA, thus creating a "notch." However, the EPE is best thought of as part of the TWP and, as we will show below, the more relevant calculation is the MTR on the combined TWP and EPE periods.

\section{EFFECTS OF DI ON LABOR SUPPLY}

\section{A. $\quad$ Expected Effects of Work-Incentive Provisions}

The DI program is designed to replace (or supplement) earnings for workers who are unable to engage in substantial gainful activity. However, as long as individuals with a disabling condition can alter their earnings by exerting different amounts of effort, the program will have work disincentives, as do all income-conditioned transfer programs, because it will induce some individuals to go onto DI rather than work. It is generally thought that these work disincentives can be reduced, though not eliminated, by low tax rates, and hence the high MTR in the DI program may create larger work disincentives than are necessary.

The framework within which work incentives of transfer program tax rates are generally analyzed is the conventional labor-leisure model. That model uses the assumption of utility maximization to justify the common-sense presumption that individuals trade off the amount of take-home income they would have for different levels of hours of work with the desire for and difficulty involved in that work. As an empirical matter, the model implies that the choice of how much to work is based partially upon how much take-home income is gained by working various amounts—or by how much is gained by working less, in the case of some transfer programs.

To apply the model, consider a population of disabled individuals eligible for the DI program. ${ }^{10}$ Let us also initially consider each of the DI phases as if work choices were made separately within each.

\footnotetext{
${ }^{10} \mathrm{We}$ assume that the individuals know with complete certainty whether they would qualify were they to apply and hence we ignore the uncertainty about eligibility which has been heavily discussed in the literature (e.g., Bound 1989; Halpern and Hausman 1986).
} 
Later we consider the combined effects of the program phases. In the first phase, the individual decides whether to go onto the rolls by applying for DI. Earnings must necessarily be low during the application and waiting periods, which will lead to lower work effort. ${ }^{11}$ Second, during the TWP, benefits are received in full regardless of earnings and the MTR is zero. DI benefits therefore generate a simple income effect, which reduces labor supply, assuming leisure is a normal good. Third, during the EPE, the labor supply effects illustrated in Figure 1 are generated. The budget constraint ADE (slope equal to the hourly wage rate) applies in the absence of the DI program, whereas ABCDE applies during the EPE; the benefit amount is $\mathrm{AB}$, the SGA level of earnings is noted on the vertical axis, and the notch at point $\mathrm{C}$ is where eligibility ends. The MTR is over 100 percent at this point. This is also the budget constraint for what might be termed a "strict" SGA program, with no EPE and no TWP — that is, the constraint that applied before those programs were introduced. A negative income effect (illustrated by arrow 1), plus a substitution effect generated by reductions in labor supply to obtain benefits (illustrated by arrow 2), both lower labor supply.

Instead of examining effects relative to no program at all, as this discussion does, one may also examine the effects of introducing the TWP and EPE into a program with only the strict SGA. As shown in Figure 2, introducing the TWP into a strict SGA program extends the budget constraint BC up to E, as

\footnotetext{
${ }^{11} \mathrm{We}$ of course are implicitly referring to averages in the population. Some portion of the eligible population would not work even in the absence of DI, and for them there is no reduction in labor supply.
} 
Figure 1

DI Budget Constraint During EPE

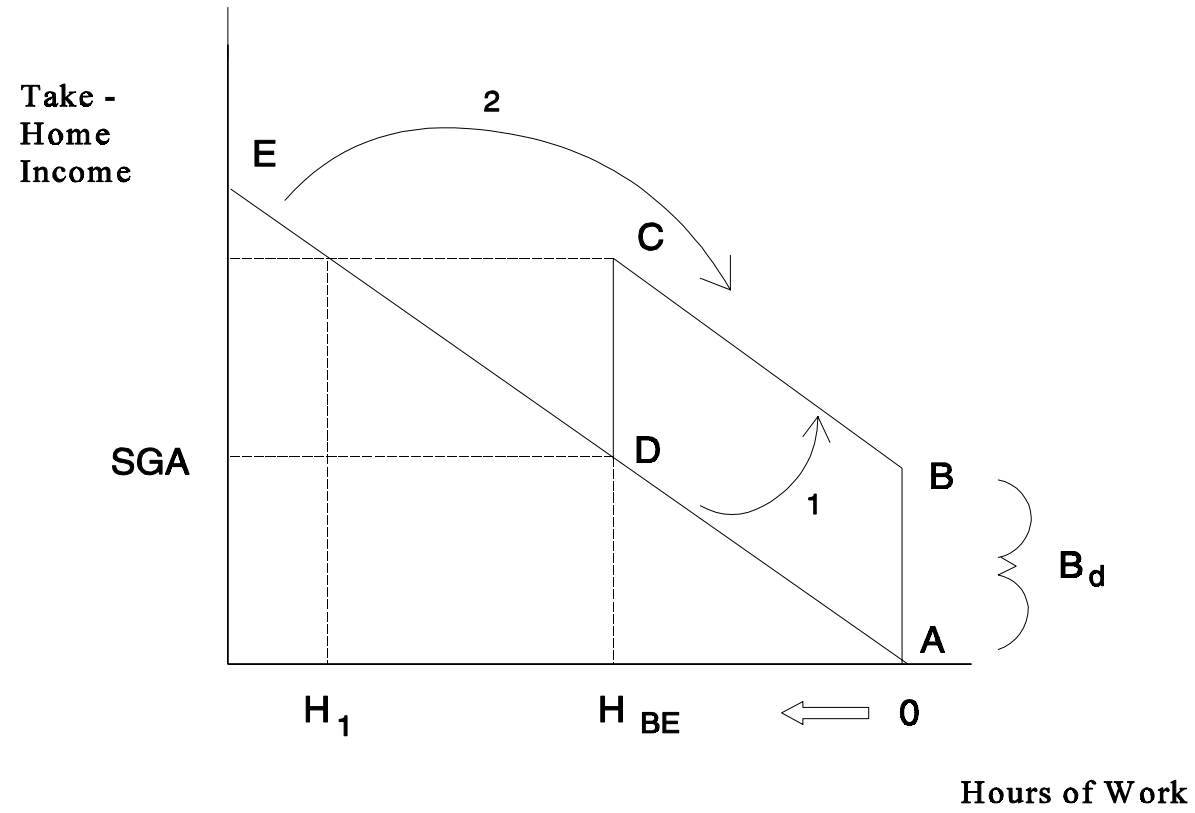

Figure 2

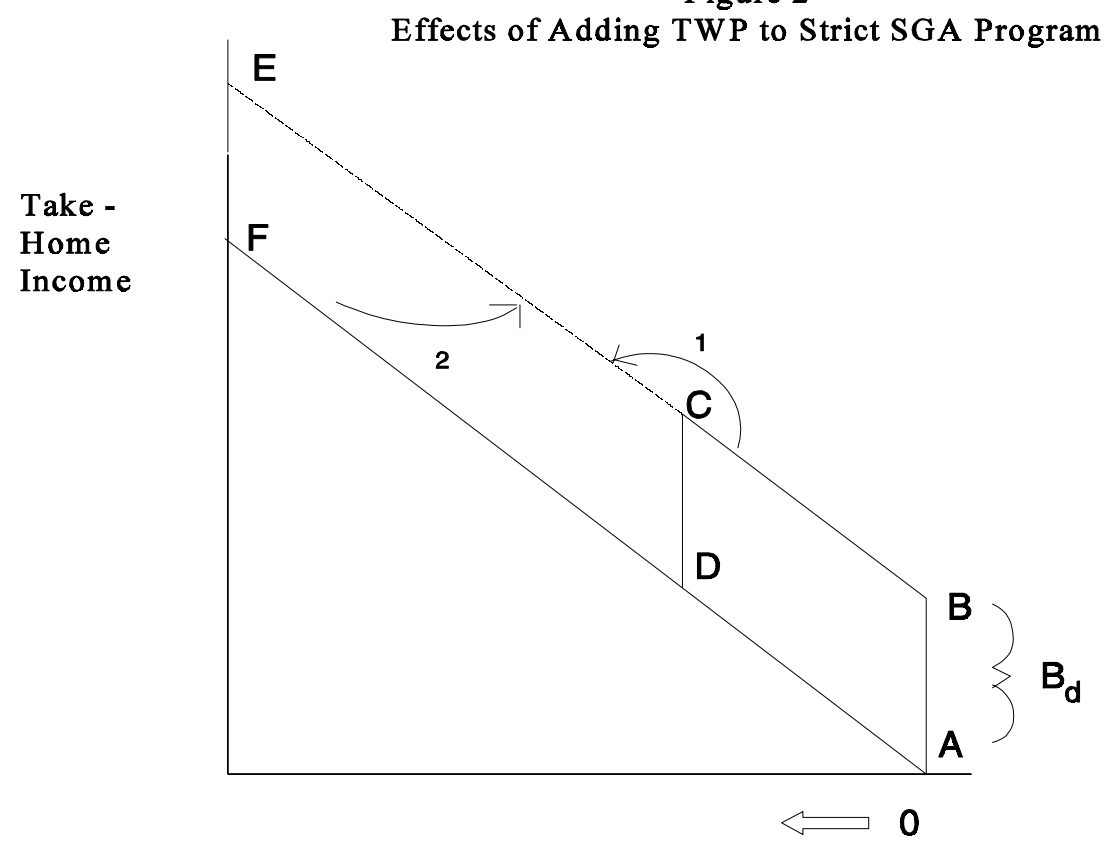

Hours of W ork 
illustrated by the dotted line, during the TWP. However, while this induces some individuals to work more, as illustrated by arrow 1 , it lowers labor supply for others, as illustrated by arrow 2 . The latter effect would occur if some individuals come onto DI after the TWP is introduced and thus represents what is sometimes called a program "entry" effect. More accurately, an individual initially working above SGA off the rolls would come onto DI to take advantage of the TWP if the advantage of the 9 months of TWP benefits outweighs the loss of benefits during the eligibility and waiting periods; thus it is the relative advantage of the combined period that is relevant (as our calculations below will show). This makes the effect of the TWP on labor supply ambiguous in sign, contrary to the presumption among policy makers that it would unambiguously increase labor supply. If the work-increasing effect were small enough, and the entry effect were large enough, average labor supply could fall. It is also clear from the diagram that the DI caseload would unambiguously rise, at least on average, since the entry effect increases the caseload while the work-increasing effect does not affect it.

The ambiguous effect of the TWP on labor supply is closely analogous to an ambiguous labor supply effect of lower marginal tax rates in the Aid to Families with Dependent Children (AFDC) program, the negative income tax, and other transfer programs (Levy 1979; Moffitt 1992). In those programs, a reduction in the MTR raises the break-even level and draws some individuals onto the rolls, thereby partially or fully offsetting whatever labor-supply-increasing effects arise from an increase in work effort among individuals initially on the rolls.

The introduction of the EPE by itself has no effect in the simple labor supply model if a strict SGA program is already in place since it is equivalent in that model to a strict SGA. To permit it to have an effect, the model would have to be modified in one of two ways. First, a fixed cost of applying for benefits could be introduced. Such a fixed cost would be incurred on initial application to DI but would not be incurred during the EPE, since the DI program keeps individuals' files "open" during that period even if they work above SGA and allows them to receive benefits if their earnings fall below SGA 
without having to go through the process of reestablishing eligibility. Second, uncertainty could be introduced into the model and the EPE could be modeled as a form of insurance, treating benefits as a source of income that is available if negative shocks to earnings are received. However, this effect by itself would not have special relevance to the EPE without the fixed costs argument, for, in the absence of fixed costs - that is, the costs of establishing eligibility — an individual could establish even initial eligibility instantly and hence the DI program as a whole would function more as short-term insurance.

A modified model which included fixed costs and, possibly, uncertainty, would show the EPE to have the same ambiguous effects on labor supply as the TWP has. This is because, relative to a program without the EPE, the implicit benefit of being on DI is increased, either because certain fixed costs no longer have to be incurred or because an implicit value (insurance) is added. This would lead some individuals who would have chosen to stay off DI altogether and to work above SGA to go onto DI and work lowered hours while on it, thereby reducing labor supply and increasing the caseload. As before, this could partially or fully offset the work-increasing effect coming from those who, in the absence of the EPE, would have worked below SGA or not at all while on the rolls.

Finally, it is worth noting that, while the ambiguous effects of the TWP and the EPE on average labor supply have been discussed in terms of possible offsetting entry effects, offsetting effects could also show up, statistically, in the program exit rate. Exit from the DI rolls occurs naturally over time as individuals' opportunities off the rolls fluctuate and sometimes improve. The TWP and EPE alter an individual's incentive to take advantage of those opportunities and to leave the rolls. Introducing the TWP can be expected to reduce the exit rate during the TWP because benefits would be higher than they were under the strict SGA; the EPE can be expected to reduce the exit rate during the EPE: individuals will be more reluctant to leave the rolls because they will incur the fixed costs of reestablishing eligibility, should they wish to come back on, and will lose the implicit insurance value. Since labor supply off the rolls is higher than on the rolls, labor supply is reduced in both cases by the fall in the exit 
rate. Thus the offsetting factors from introducing the TWP and EPE, if they are present, may show up in both increased entry to, and decreased exit from, the program. We shall simulate numerically the amounts by which the TWP and EPE increase the income gains from entry and increase the income losses from exit.

\section{B. Evaluating Work-Incentive Provisions Using Existing Research}

To evaluate the work-incentive provisions of the DI program, we need to know the sensitivity of recipient work effort to changes in net wages (or MTRs) and in income opportunities. To estimate the magnitudes of possible entry and exit effects, we also need to know how potentially eligible individuals respond to changes in MTRs and benefit levels and how recipient exit decisions respond to those variables. Unfortunately, the existing empirical research does not provide estimates of the substitution and income effects needed to make these calculations.

Many empirical studies have examined the effect of DI benefits level on program participation (or caseload size). ${ }^{12}$ Participation in DI is typically estimated as a function of the potential DI benefit—imputed for those not on the program—and individual characteristics such as age and education, and locational characteristics. The main parameter of interest, the elasticity of DI participation with respect to the DI benefit, varies widely in the literature, ranging from 0.06 to 1.80 .

These results, while important for some applications, fall significantly short of what is needed to estimate the effect of the TWP, the EPE, or proposed changes to these work-incentive provisions. In the absence of direct evaluations of the TWP, for example, inferences about its effects could be made only by estimating the number of individuals who would prefer to work above SGA but still receive benefits; and wage elasticities as well as income elasticities are needed for this prediction. The marked absence of attempts at estimated wage elasticities is, in fact, the major defect of this literature for assessing the

\footnotetext{
${ }^{12}$ This literature is critically reviewed in Leonard 1986 and Hoynes and Moffitt 1996, and the exchanges between Parsons 1984 and Haveman and Wolfe 1984 and Parsons 1991 and Bound 1991.
} 
effectiveness of work-incentive provisions. ${ }^{13}$ Furthermore, in these studies, participation in DI is considered equivalent to nonparticipation in the labor market. This rules out examining the sort of responses shown by the arrows in Figures 1 and 2.

\section{Income, Earnings, and Tax Rates under Current Law: Simulations}

Although the existing DI literature does not permit us to make reliable predictions for the net work effort and caseload effects of the work-incentive provisions, we can obtain some notion of the incentives to work and take up DI benefits by calculating the income gain or loss associated with different work-effort levels and program participation statuses, and the implicit tax rates that result. We shall therefore provide numerical simulations of those variables for individuals with different benefit and wage levels. However, the preceding analysis has made clear that individual decisions are no doubt made not within each phase alone, but taking into account all phases together. Therefore we shall be most interested not in the monthly MTRs within, say, the TWP or the EPE, but rather the implicit MTR which applies to an entire sequence of labor supply values over all phases of DI receipt. This will become clearer momentarily.

To begin our simulation, we consider an individual at the time of onset of disability. The disabled individual is assumed to be out of the labor force for 12 months -5 months for the waiting period and 7 more months for "recuperation"- - before the option of reentering the workforce is possible. We then consider the consequences of entering the workforce at some specific level of work. We consider five work-level alternatives: no work, 10 hours per week, 15 hours week, 20 hours per week, or

\footnotetext{
${ }^{13}$ Some of the studies (e.g., Parsons 1980a and 1980b) do include wages but only their pre-disability level, and only in the form of a replacement rate, which results in neither an income nor a wage elasticity. Obtaining estimates of wage and income elasticities for DI recipients is difficult. For example, the DI benefit itself is endogenous due to its relationship to previous work experience. Furthermore, DI receipt is uncertain, and it is difficult to impute DI benefits for nonrecipients. These issues and their relevance for the empirical literature are discussed in Leonard 1986, Haveman and Wolfe 1984, and Bound 1991.
} 
40 hours per week. To simplify the calculations, we assume, for our initial simulations, that the recipient continues with this level of work effort indefinitely.

We consider a recipient's time horizon over a period of 57 months, representing the minimum time an individual would need to complete all phases of DI receipt, all the way to the end of the EPE. ${ }^{14}$ In each month, we calculate a recipient's earnings and DI benefit given the program rules, his wage, work effort, and benefit level. We consider the wage and benefit levels associated with three types of workers: "low-wage" workers are those who worked at the federal minimum wage for their entire work history, "medium-wage" workers have earned the average wage over their career, and "high-wage" workers have earned 150 percent of the average wage for their career. Each of these three types of workers is assigned the appropriate DI benefit that results from this work history. ${ }^{15}$ Further, we assume that the onset of the disability reduces the wage by 25 percent (Bound 1989). ${ }^{16}$ Continuing DI eligibility and applicable benefit payments are then calculated each month using the rules outlined in Part 2. For each period, both wages and benefits are adjusted for nominal wage growth at an average annual rate of 5 percent. This is the intermediate assumption used for the projections of the Social Security Trust Fund (U.S. House of Representatives 1994). Finally, we calculate the present discounted value of the income and earnings

${ }^{14}$ The 57-month horizon is the sum of the 5-month waiting period, 7 months of recuperation, 9 months of TWP, and 36 months of EPE. This time horizon could be extended but would not change the nature of the tradeoffs we illustrate. Because we assume that individuals enter the workforce after 12 months of recuperation, our DI recipients receive benefits for a minimum of 19 months ( 7 months of recuperation, 9 months of TWP, 3-month grace period) and are out of the labor force for a minimum of 24 months (including a 5-month waiting period before benefit receipt).

${ }^{15}$ These wage/benefit scenarios are used by the Social Security Administration to illustrate benefits for typical workers (see Social Security Administration 1995, Table 2.A26). The "average" worker is the average for the labor force covered by Social Security, which may be higher than the average among DI recipients (Bound 1989).

${ }^{16}$ The low-wage (minimum wage) worker does not incur the 25 percent decrease in wages. The postdisability wage levels used are $\$ 4.90$ for low-wage, $\$ 8.34$ for average-wage, and $\$ 12.51$ for high-wage workers. Benefits equal $\$ 557, \$ 880$, and $\$ 1134$. 
stream for each of the three benefit-wage scenarios for each of the labor supply choices using a discount rate of 7 percent. ${ }^{17}$

Appendix Tables A1 and A2 summarize our calculations, and Table 1 and Figure 3 show the main features. The appendix tables show the actual discounted present values of earnings, benefits, and net income for the different types of workers under current law and under a strict SGA (that is, without the TWP and EPE) and these are illustrated in Figure 3 for a medium-wage worker. Under current law, as hours of work for the medium-wage worker increase from 0 to 10 per week, the present discounted value (PDV) of net income increases because earnings stay below SGA (the PDV of benefits therefore remains unchanged); but income then drops drastically with further hours of work because the SGA is exceeded, and hence benefits drop to zero at the point at which the individual passes from the TWP into the EPE. Additional increases in labor supply increase total income because earnings go up and the PDV of benefits-from the initial 12-month period and the 9-month TWP—are unchanged.

Table 1 shows the marginal and average tax rates corresponding to the figure for all three types of workers. The MTR is zero for both the low-wage and medium-wage workers up to 10 hours per week, but the SGA is hit between 10 and 20 and hence MTRs exceed 100 percent. The high-wage worker hits the SGA between 0 and 10 hours per week instead. Average tax rates, which are more relevant for the nonworking DI recipient who is considering making a discrete jump to either 10, 20, or 40 hours per

\footnotetext{
${ }^{17}$ Since we assume nominal wage growth of 5 percent per year, this implies a real interest rate of approximately 2 percent.

We do not include deductions for federal, state, or payroll taxes and hence net income includes earnings plus DI benefits. Including these taxes would lead to a higher MTR but would not change the substantive points on the effects of DI on earnings possibilities.
} 


\section{TABLE 1}

Tax Rates in the DI Program under Current Law and Strict SGA programs, by Wage Level and Hours of Work

\begin{tabular}{|c|c|c|c|c|c|c|}
\hline & \multicolumn{3}{|c|}{ Marginal Tax Rate $(\%)^{\mathrm{a}}$} & \multicolumn{3}{|c|}{ Average Tax Rate $(\%)^{\mathrm{b}}$} \\
\hline & $10 \mathrm{hrs}$. & $20 \mathrm{hrs}$. & $40 \mathrm{hrs}$. & $10 \mathrm{hrs}$. & $20 \mathrm{hrs}$. & $40 \mathrm{hrs}$ \\
\hline \multicolumn{7}{|c|}{ Low-Wage Worker } \\
\hline Current law & 0 & 124 & 32 & 0 & 62 & 47 \\
\hline Strict SGA & 0 & 124 & 67 & 0 & 62 & 65 \\
\hline \multicolumn{7}{|c|}{ Medium-Wage Worker } \\
\hline Current law & 0 & 174 & 0 & 0 & 87 & 44 \\
\hline Strict SGA & 0 & 240 & 0 & 0 & 120 & 60 \\
\hline \multicolumn{7}{|c|}{ High-Wage Worker } \\
\hline Current law & 150 & 0 & 0 & 150 & 75 & 37 \\
\hline Strict SGA & 206 & 0 & 0 & 206 & 103 & 52 \\
\hline
\end{tabular}

Note: The table presents results of simulation over a 57-month period.

${ }^{\mathrm{a}} \mathrm{MTR}$ are calculated as one minus the change in income over the change in earnings resulting from increasing hours of work from the prior level.

${ }^{\mathrm{b}}$ ATRs are calculated as one minus the change in income over the change in earnings resulting from increasing hours of work from the "no work" choice. 


\section{FIGURE 3}

Income Opportunities for DI Participants, Medium-Wage Worker
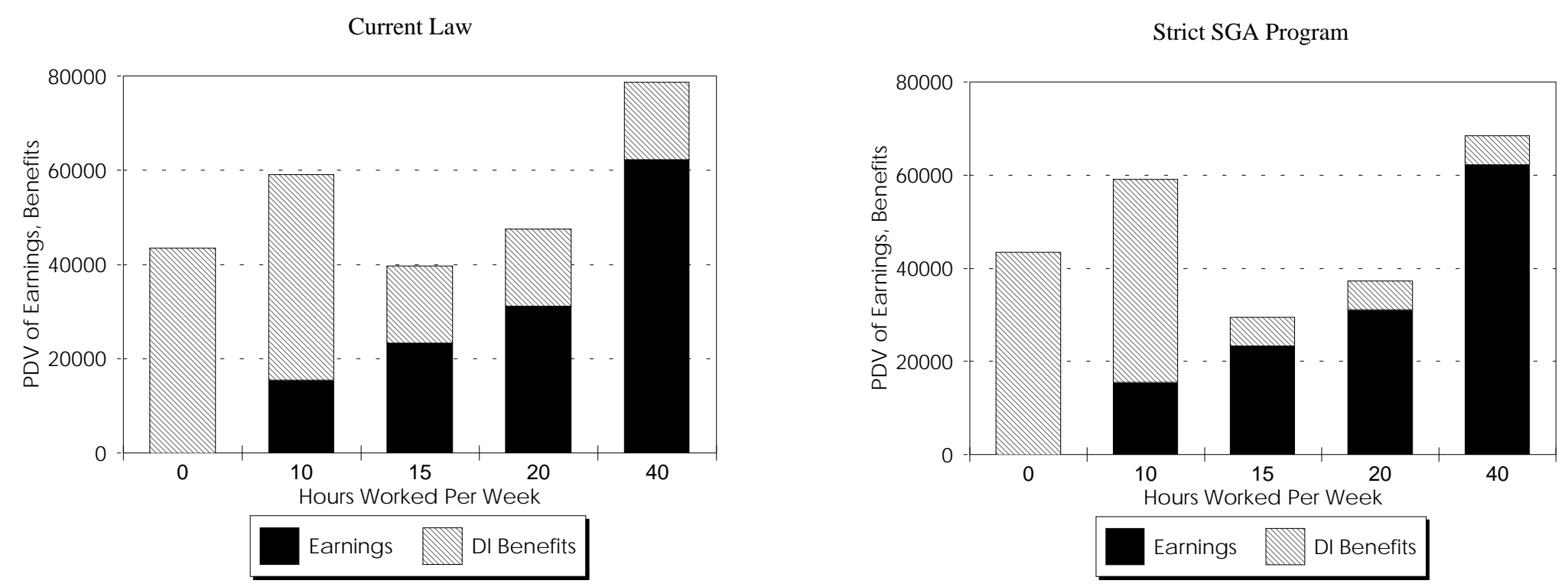
week, are often lower because the notch has less of an effect (since a wider range of the budget constraint is considered). ${ }^{18}$

Under a strict SGA program, a comparison of the two panels in Figure 3 shows that income is lower than under current law for hours of work greater than 10 per week because the TWP allows 9 months of benefits while working, which is not allowed under a strict SGA program. This has two implications. First, it means that a strict SGA program would have higher MTRs and average tax rates (ATRs) than under current law, and this is illustrated in Table 1. The difference is often large-MTRs often exceed 200 percent—and it could be expected that some initially nonworking recipients would increase their labor supply as a result of current law (compared to a strict SGA program). Second, however, the higher net income amounts at hours greater than 10 implies that the DI program is more attractive under current law than it would be under a strict SGA program, and this can be expected to increase entry and decrease exit, thereby increasing the caseload and reducing work effort among new entrants. As shown in Appendix Tables A1 and A2, the increase in the PDV of income is often on the order of from 15 to 20 percent. To take one example, under current law a medium-wage worker who leaves a 20-hour-a-week job to go onto DI to work 15 hours per week during the TWP and after, would experience a 27 percent increase in net income, despite the lower work level; whereas under a strict SGA program he would experience a 6 percent loss in net income. ${ }^{19}$ Obviously, he would be less likely to go onto DI under a strict SGA. This necessarily implies that a DI recipient who has chosen to work 15 hours per week during the TWP and who locates a 20-hour-per-week job off DI would lose income under

\footnotetext{
${ }^{18}$ The low-wage worker experiences a nonzero MTR going from 20 to 40 hours per week because we assume nominal wage rates grow at 5 percent per year but the SGA stays fixed in nominal terms. At 20 hours per week, the individual hits the SGA partway through the EPE; at 40 hours per week, he hits it at the beginning of the EPE. We choose to conduct the simulation in this way because it reflects actual, current law: the SGA is not indexed and is typically held fixed for many years.

${ }^{19}$ In Table A1, .27=(\$39,688-\$31,171)/\$31,171 and in Table A2, .06=(\$31,171-\$29,447)/\$31,171.
} 
current law if he leaves the rolls to take that job, but he would gain income under the strict SGA program.

\section{REFORMING WORK INCENTIVES IN THE DI PROGRAM}

As we noted in the introduction, methods for increasing work incentives in the DI program continue to be discussed. In this section we will consider several of the reforms that have been proposed, including a simple reduction in the MTR akin to a negative income tax. We will consider both the theoretically expected effects and then conduct numerical simulations for their effects on tax rates and income.

\section{A. Alternative Work-Incentive Provisions}

To stick close to reforms actually being proposed, we examine five changes to the DI program:

(1) index the SGA amount to keep pace with wage growth;

(2) provide a partial offset (MTR) of 50 percent on earnings above the monthly SGA, to be imposed after the TWP;

(3) provide a partial offset (MTR) of 50 percent on earnings above $\$ 85$ a month, to be imposed after the TWP;

(4) extend the TWP by 12 months; and

(5) provide an earnings subsidy for disabled individuals.

The first four proposals were proposed by a panel of experts (National Academy of Social Insurance 1994) and the fifth was proposed by Burkhauser and Daly (1996). Some of these proposals have made their way into recent congressional bills. In particular, the Jeffords bill (Work-Incentive and SelfSufficiency Act of 1996) proposes to turn the DI program into a strict SGA program enhanced with an MTR of 50 percent over SGA. The Transition to Work Act of 1997 includes a refundable tax credit modeled after the Earned Income Tax Credit (EITC) which would be available to those who lose DI 
benefits because of increases in earnings. No further congressional action has been taken on these proposals.

The first reform simply increases the SGA and hence has a clear work-incentive rationale. The second and third reforms lower the MTR, as in a negative income tax, below 100 percent, and therefore eliminate the notch in the budget constraint. In one case the lower tax rate begins only above SGA, whereas in the other case it begins at $\$ 85$ per month, an estimate of average work expenses. Since the SGA is currently $\$ 500$ per month, this latter change would actually increase the MTR over some low ranges of hours worked. The fourth reform simply extends the TWP for twelve months on top of the current nine.

The fifth proposed reform differs substantially from the first four in that, for the most part, it would operate outside the DI system. We assume that the earnings subsidy is made available to the same population of disabled individuals as is currently eligible for DI. In our simulations, we consider an earnings subsidy equal in magnitude to the 1995 EITC. The EITC is an earnings subsidy in the form of a refundable tax credit and is typically available only to families with children. ${ }^{20}$ Our simulation therefore can be thought as extending the EITC to all disabled workers, regardless of whether they have a child. ${ }^{21}$ The amount of the EITC depends on whether earnings fall in the subsidy, flat, or phaseout range of the credit. The subsidy range covers earnings up to $\$ 6,160$, over which the subsidy equals 34 percent of earnings, generating a maximum credit of $\$ 2,094$. In the flat range, covering earnings between $\$ 6,160$ and $\$ 11,290$, the worker receives the maximum credit. In the phaseout range, the subsidy is reduced by

\footnotetext{
${ }^{20}$ The credit was introduced in 1975 to offset the social security tax but has been expanded significantly since the mid-1980s. Starting in 1994, a small EITC was made available to childless workers with earnings up to $\$ 9,000$.

${ }^{21}$ In particular, we provide the EITC which is extended to families with one child. Since 1991, a more generous EITC has been made available to families with two or more children.
} 
15.98 cents for each additional dollar in earnings such that the credit is fully phased out at earnings of $\$ 24,396 .^{22}$ Workers earning more than $\$ 24,396$ are not eligible.

\section{B. Expected Effects of Changes to DI Work Incentives}

An increase in the SGA increases the notch point in the budget constraint and hence leads to increases in work effort among current recipients. However, it increases the DI caseload by drawing some of the eligible population onto the rolls and hence has ambiguous impacts on average work effort among the disabled. These effects would manifest themselves in both the application phase and the EPE. In the application phase, the higher level of SGA would permit workers to work more while waiting for benefits to begin, but would for that same reason lower the costs (or raise the benefits) of going onto DI among disabled individuals who are working off DI. During the EPE, as illustrated in Figure 4, an increase in the notch point encourages additional work among those initially at the notch (arrow 1), but lowers labor supply among those above the initial level of SGA. Some of the latter individuals (arrow 2) are made eligible by the increase in SGA and some (arrow 3) are encouraged to reduce earnings to be at or below the new SGA, but in either case work effort falls and the caseload rises.

Similarly, adding a partial benefit or MTR on earnings during the EPE will tend to increase work levels among current DI recipients, but the impact on overall work effort among the disabled is indeterminate in direction. Figure 5 shows this change. The budget constraint under current law during the EPE is ABCDE. Adding an MTR of 50 percent above SGA gets rid of the notch and phases out benefits at a rate of 50 cents for each dollar earned over SGA, shown by the segment CE, with a slope of one-half the wage. This reform has some positive work incentives for those initially at the notch (arrow 1) but work disincentives for those who come onto the rolls (arrows 2 and 3). The caseload

\footnotetext{
${ }^{22} \mathrm{We}$ use the parameters of the current EITC program for convenience. In practice, an earnings subsidy for disabled workers could also take the form of subsidies to the employer. At the level of generality of our simulation program, these are equivalent.
} 
Figure 4

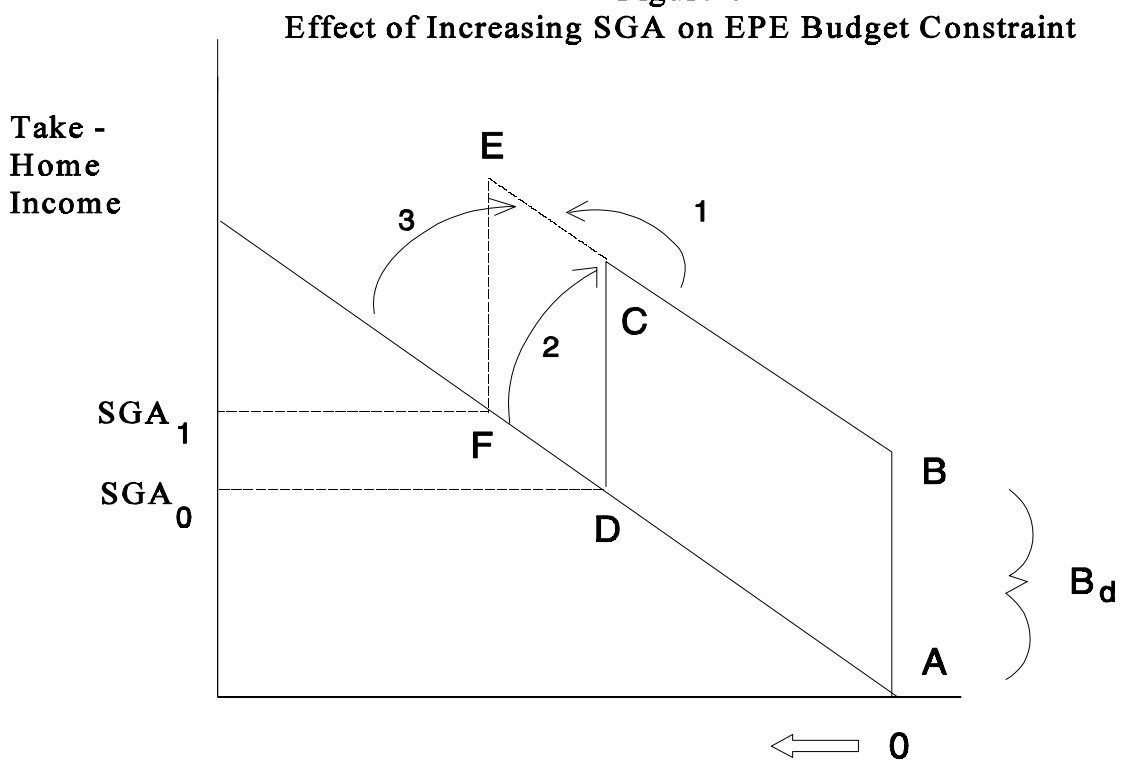

Hours of Work

Figure 5

Effects of Adding 50\% MTR over SGA

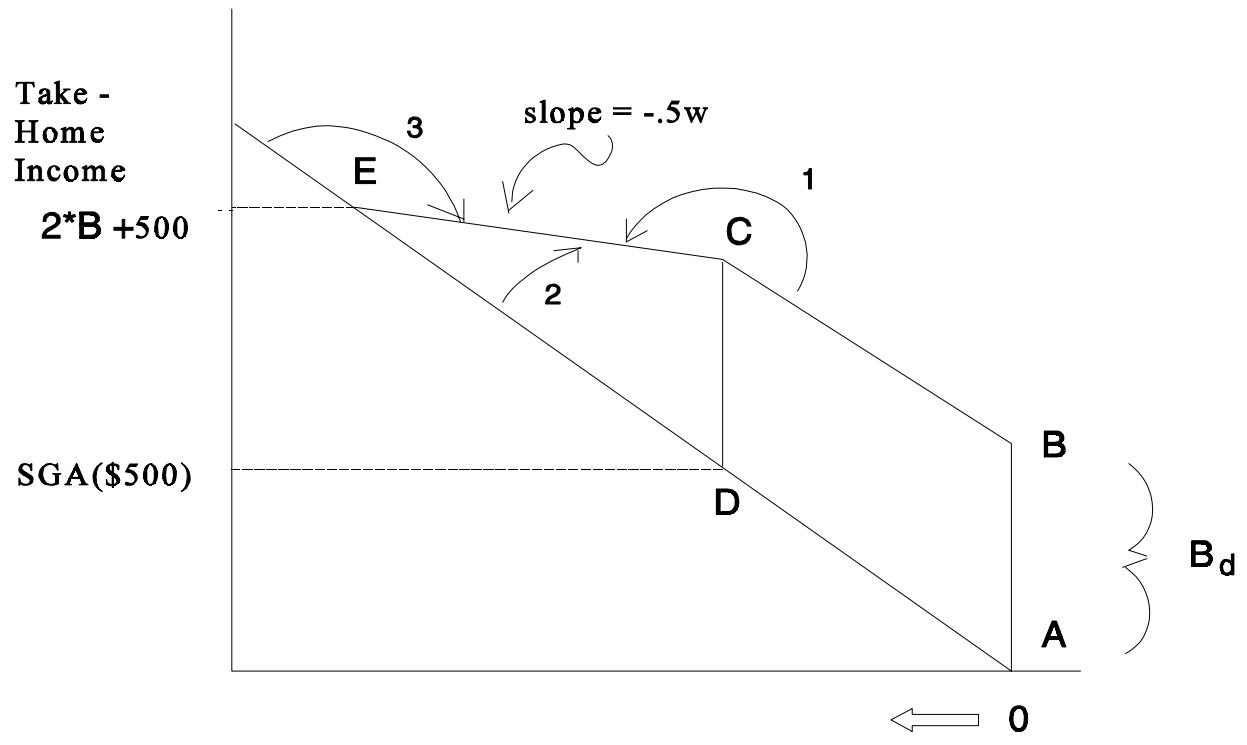

Hours of Work 
unambiguously rises. The potential increase in the caseload is quite large under this expansion: using the average benefit in 1993 of $\$ 642$, the break-even earnings level increases from $\$ 500$ per month (current SGA) to about $\$ 1800$ per month or $\$ 22,000$ per year. ${ }^{23}$

Imposing a 50 percent MTR on earnings over an $\$ 85$ exclusion during the EPE differs from the other reforms because benefits would be lower than they are under current law for some ranges of earnings, for the $\$ 85$ exclusion is below the SGA level of $\$ 500$. By increasing the tax rate (from 0 to 50 percent) in ranges less than $\$ 500$, we may see a reduction in work effort for current recipients. However, by eliminating the notch (and its high MTR) and extending benefits past the SGA, we may see an increase in work levels among some recipients. For this program change, the caseload as well as the net work effects are ambiguous. The direction of the change in entry and exit rates is not determinant since for some hours ranges the program has been expanded, while for others the program is less generous.

Increasing the length of the TWP allows recipients to work for more months before being taxed (e.g., before entering the EPE); hence the effective MTR (in present-value terms) decreases. This can be expected to increase work levels and to increase the length of time spent in the program for current participants. However, it can also be expected to attract new participants and to reduce exit rates, both of which will reduce work-effort levels and increase the size of the caseload.

The earnings subsidy differs from the other policy changes because it affects income off the DI program instead of on it. For this reason, we call it non-DI reform. Unlike the other policy simulations, the introduction of a pure earnings subsidy unambiguously increases labor supply and reduces the size of the DI caseload. Labor supply increases because the return to an hour of work increases at all levels of hours of work. Program participation decreases, at minimum, because increases in labor supply will often lead individuals off the DI rolls. For those who stay on the DI rolls, the effect of an earnings subsidy on

\footnotetext{
${ }^{23}$ The benefit formula becomes DIBEN - 0.5*(EARNINGS- 500), which using a DIBEN of \$642 equals zero when earnings equal $2 * 642+500$ or $\$ 1784$.
} 
labor supply depends on how the subsidy is treated by the program. If it is ignored by the program altogether, labor supply will increase while on DI; but if it is included as earnings for the purpose of SGA calculation, it will imply that the SGA is hit at an earlier hours point and this will have separate effects. In our simulations below, we assume the latter treatment. However, the EITC, upon which we model our earnings subsidy, has "flat" and "phaseout" ranges, which are well-known to induce reductions in labor supply for those already working (Eissa and Liebman 1996). Therefore, on net, the effect of this type of earnings subsidy on labor supply is ambiguous as well. ${ }^{24}$

\section{Income, Earnings, and Tax Rates under Alternative Work Incentives}

In this section we apply the same simulation model we used previously to simulate the effects of the five reforms under discussion. For the four DI reforms, Appendix Tables A3 to A6 present the PDVs of earnings, benefits, and net income at different hours of work for the three wage levels. The results are summarized in Table 2.

The first reform, indexing the SGA, pushes the SGA up to a higher hours level. This affects MTRs and ATRs at the hours points we show only for the low-wage worker, who now does not hit the notch until 40 hours per week. The medium-wage and high-wage workers hit the notch at the same discrete hours point as before. Therefore, at least for the low-wage recipient, there is reason to expect increased work incentives from this reform.

Reducing the MTR eliminates the notch entirely during the EPE; hence there are no more excessively high MTRs facing DI recipients (simulations 3 and 4). The MTRs fall from their current levels of as high as 174 percent, for the medium-wage worker, to 23 or 36 percent, for example.

\footnotetext{
${ }^{24}$ Because the EITC is available only to workers, it unambiguously leads to higher rates of labor force participation. Empirical studies have shown that the added worker effect seems to dominate the potential reduction in labor supply among current workers to lead to a net increase in labor effort for single mothers (Eissa and Liebman 1996) but not necessarily among married couples who, typically, have larger initial labor force participation rates (Eissa and Hoynes 1997).
} 
TABLE 2

Tax Rates in the DI Program under Current Law and Proposed DI Reforms, by Wage Level and Hours of Work

Marginal Tax Rate (\%)

$10 \mathrm{hrs}$.
$20 \mathrm{hrs}$.

$40 \mathrm{hrs}$.
Average Tax Rate $(\%)^{\mathrm{b}}$ $10 \mathrm{hrs}$. $20 \mathrm{hrs}$. $40 \mathrm{hrs}$.

Low-Wage Worker

1. Current law

2. Index SGA

3. $50 \%$ MTR over SGA

4. $50 \%$ MTR over $\$ 85$

5. Extend TWP 12 months

$\begin{array}{rrr}0 & 124 & 32 \\ 0 & 0 & 94 \\ 0 & 0 & 31 \\ 24 & 36 & 36 \\ 0 & 118 & 0\end{array}$

$\begin{array}{rrr}0 & 62 & 47 \\ 0 & 0 & 47 \\ 0 & 0 & 15 \\ 24 & 30 & 33 \\ 0 & 59 & 30\end{array}$

Medium-Wage Worker

1. Current law

2. Index SGA

3. $50 \%$ MTR over SGA

4. $50 \%$ MTR over $\$ 85$

5. Extend TWP 12 months

$\begin{array}{rrr}0 & 174 & 0 \\ 0 & 174 & 0 \\ 0 & 23 & 36 \\ 29 & 36 & 36 \\ 0 & 110 & 0\end{array}$

$\begin{array}{rll}0 & 87 & 44 \\ 0 & 87 & 44 \\ 0 & 12 & 24 \\ 29 & 33 & 35 \\ 0 & 55 & 27\end{array}$

\section{High-Wage Worker}

1. Current law

150
150
3
32
94

0
0
36
36
0

0
0
36
36
0

$\begin{array}{r}150 \\ 150 \\ 32 \\ 94 \\ \hline\end{array}$

$\begin{array}{ll}75 & 37 \\ 75 & 37 \\ 20 & 28 \\ 34 & 35 \\ 47 & 24\end{array}$

Note: The table presents results of simulation over a 57-month period.

${ }^{a}$ Marginal tax rates are calculated as one minus the change in income over the change in earnings resulting from increasing hours of work from the prior level.

${ }^{b}$ Average tax rates are calculated as one minus the change in income over the change in earnings resulting from increasing hours of work from the no work choice. 
However, the magnitude of this decline is somewhat exaggerated because, while the high MTR at the notch point is eliminated, the MTR over hours of work beyond that is increased. Thus, for example, for both medium-wage and high-wage workers, the MTR above the (old) SGA level rises from 0 to 36 percent. This is a necessary consequence of having to phase out benefits and illustrates the general principle that the elimination of a notch is akin to taking a very high MTR at one point and spreading it out over other points, raising the MTRs at many of those other points. This can also be seen in Table 2 inasmuch as the reduction in ATRs is considerably less than the reduction in MTRs (see also Figure 5). The labor supply effects of the change are therefore ambiguous. ${ }^{25}$

Extending the TWP by twelve months generally lowers MTRs and ATRs because the individual faces a tax rate of zero for a larger fraction of the simulation period. This has little effect on the highwage worker but lowers tax rates for the low-wage worker by a considerable amount, suggesting that positive effects on labor supply could result.

Table 3 and Figure 6 illustrate the effects of an earnings subsidy on tax rates and income. The first earnings subsidy we illustrate assumes that the DI program ignores the subsidy amount entirely except when comparing earnings to SGA ("earnings subsidy for all disabled workers"). The second earnings subsidy we examine is one that does not allow the subsidy to be received by workers who are on the DI rolls. Much of the employment obtained by DI recipients is in sheltered work environments outside the regular labor market, and it is not clear that the earnings from those jobs would be treated as available for subsidy. Alternatively, the DI program could treat the earnings subsidy as a form of nonlabor income and subject it to 100 percent tax, which would also effectively make it unavailable to DI recipients. An earnings subsidy not available to DI recipients should give the individual a somewhat

\footnotetext{
${ }^{25}$ The benefit rate reduction over $\$ 85$ also increases the MTR at very low-hours ranges, as noted previously in the text.
} 


\section{TABLE 3}

\section{Tax Rates in the DI Program under Current Law and Non-DI Reforms, by Wage Level and Hours of Work}

Marginal Tax Rate $(\%)^{\mathrm{a}}$

$10 \mathrm{hrs}$.
$40 \mathrm{hrs}$.

124
154

$91 \quad 20$

32

$-5$

20
Average Tax Rate (\%) 10 hrs. 20 hrs. 40 hrs.

Low-Wage Worker

1. Current law

0

0

$-34$

62

$60 \quad 27$

3. Earnings subsidy for non-DI recipients only

0

0

46

33

Medium-Wage Worker

1. Current law

$\begin{array}{rr}0 & 174 \\ 140 & -12\end{array}$

0

12

0
140

$87 \quad 44$

2. Earnings subsidy for all 140

3. Earnings subsidy for non-DI recipients only

0

140

9

0

$64 \quad 38$

High-Wage Worker

1. Current law

2. Earnings subsidy for all 120

0

0

150

$13 \quad 120$

75

62

37

3. Earnings subsidy for non-DI recipients only

4

9

127

Note: The table presents results of simulation over a 57 -month period.

${ }^{a}$ Marginal tax rates are calculated as one minus the change in income over the change in earnings resulting from increasing hours of work from the prior level.

${ }^{\mathrm{b}}$ Average tax rates are calculated as one minus the change in income over the change in earnings resulting from increasing hours of work from the no work choice. 
FIGURE 6

Income Opportunities for DI Participants, Medium-Wage Worker

(a) Earnings Subsidy for Non-Recipients

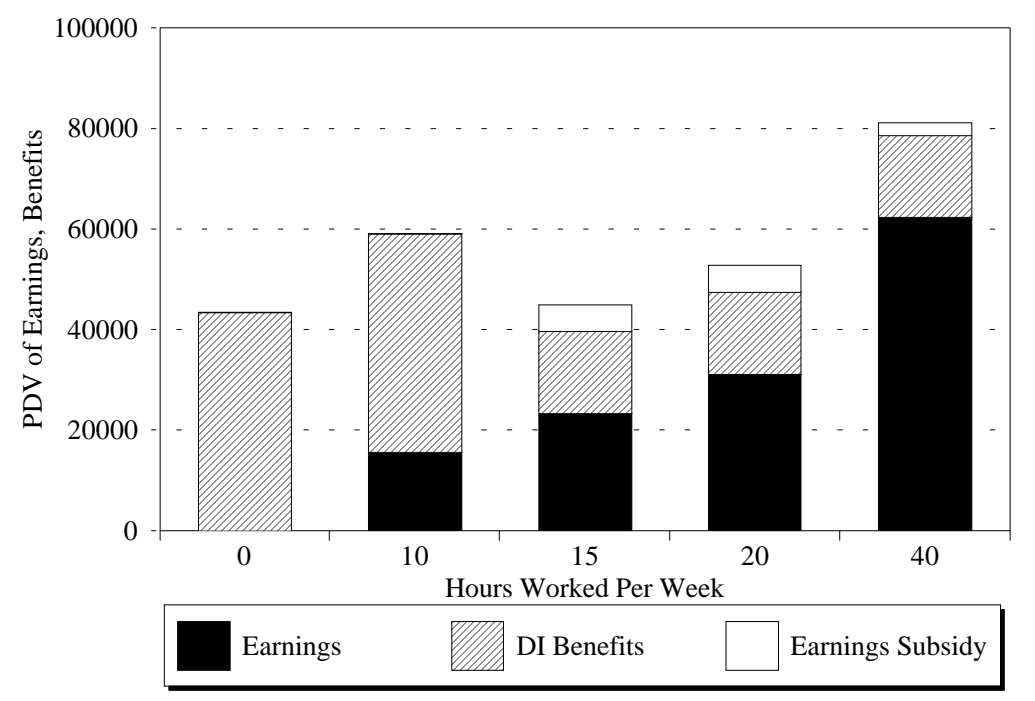

(b) Earnings Subsidy for All Disabled Workers

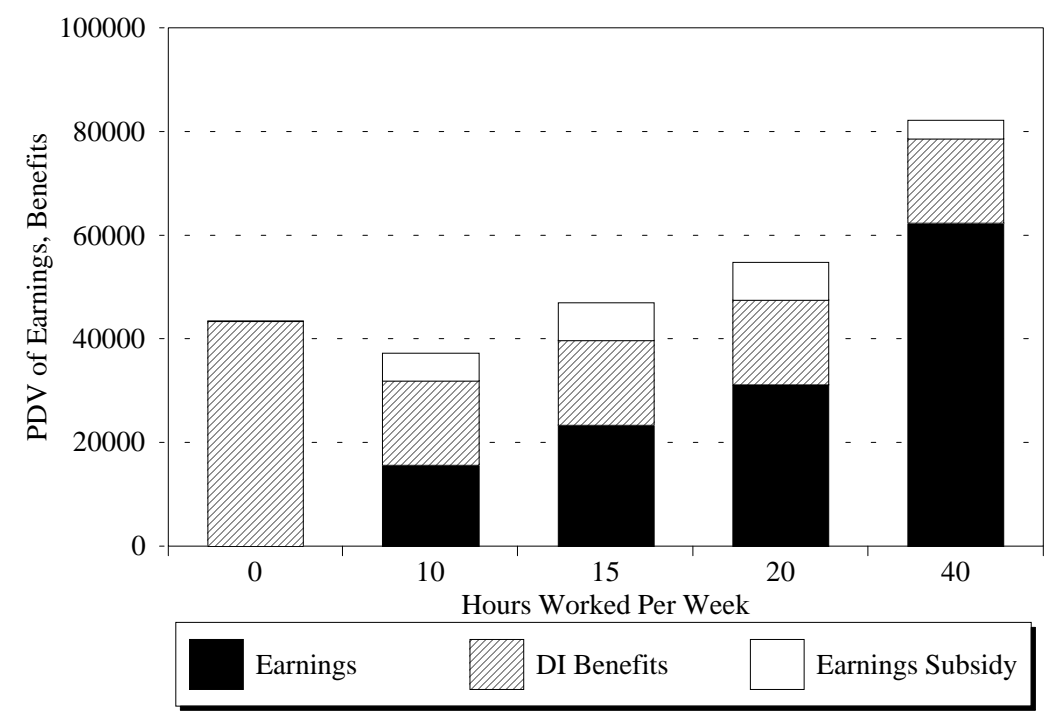


larger incentive to increase labor supply and to leave the DI rolls than the universal earnings subsidy available both to recipients and nonrecipients.

Figure 6 shows that, under the earnings subsidy for all disabled workers, net income levels rise monotonically (except for the initial SGA point). This is reflected in Table 3, which shows the MTR to change from positive to negative for the low-wage worker at two of the hours points. The inclusion of the earnings subsidy in the SGA determination implies a higher MTR when going from 10 to 20 hours, but the more relevant ATRs show a reduction throughout the entire range from the reform. MTRs and ATRs generally fall at the 20 and 40 hours points for the medium-wage and high-wage workers, although little for the latter, who receive only a small subsidy.

Under the earnings subsidy available only to non-DI recipients, Figure 6 shows that income amounts are the same as in Figure 1 except for the addition of the earnings subsidy at hours of work of 15 or more, when the individual is off DI. In Table 3 it can be seen that this earnings subsidy has a mixed set of effects on the MTRs and ATRs relative to the universal subsidy, sometimes increasing them and sometimes decreasing them depending on the hours point and the individual wage level. ${ }^{26}$

For the most part, the results presented thus far show the possible labor supply increases and caseload reductions from many of the reforms. They do not show, at least directly, the offsetting changes in incentives for entry and exit that would be associated with many of those reforms. Tables 4 and 5 illustrate those effects by showing the percentage gains and losses in net income that would result from movements off, or onto, the rolls at different hours points under current law and under the reforms for a medium-wage individual. Thus, Table 4 shows exit-rate incentives by illustrating the changes in net income that would result from being initially on the rolls (when net income includes the PDV of benefits) but then moving off the rolls (when net income only includes the PDV of earnings) at the end of

\footnotetext{
${ }^{26}$ Earnings subsidies are most effective for encouraging work among low-wage workers. The subsidy could easily be expanded to provide greater incentives for higher-wage workers.
} 


\section{TABLE 4}

Percentage Change in Income from Leaving DI under Current Law and Alternative Policies, Medium-Wage Recipient

\begin{tabular}{lcccc}
\hline & \multicolumn{4}{c}{ Percentage Change in Income by Hours Worked $^{\mathrm{a}}$} \\
\cline { 2 - 5 } & 20 hrs. & 40 hrs. & $0-20$ hrs. & $20-40$ hrs. \\
\hline Current law & 0 & 0 & -10 & 48 \\
Strict SGA & 0 & 0 & -10 & 61 \\
& & & & \\
DI Reforms & & & -10 & 48 \\
$\quad$ Index SGA & 0 & 0 & -10 & -1 \\
$\quad$ 50\% MTR over SGA & -33 & -13 & -10 & 9 \\
$\quad$ 50\% MTR over \$85 & -26 & -7 & -10 & 22 \\
$\quad$ Extend TWP by 12 months & -17 & -11 & & 36 \\
Reforms outside DI & & & 2 & 38 \\
$\quad \begin{array}{l}\text { Earnings subsidy } \\
\text { Earnings subsidy, non-DI }\end{array}$ & 0 & 0 & 2 & \\
\hline
\end{tabular}

Note: The recipient is assumed to leave DI after two years on the program. Under current law (and given our one-year recuperation period) this occurs at the end of the TWP. For comparability, when we simulated extending the TWP, we still considered an exit from the program after two years. All simulations cover a 57-month period.

${ }^{a}$ The scenarios in the first two columns assume that the worker does not change hours of work when leaving DI. In the last two columns, the worker is assumed to increase hours worked when leaving the program, to the levels given. 
the TWP. Under current law and the strict SGA, for example, the medium-wage worker is above the SGA at 20 hours per week and at 40 hours per week; hence leaving the rolls and continuing to work at these hours would not affect net income. Column three shows that increasing hours of work from 0 to 20 when going off would result in net-income losses because earnings would not be enough to make up for the benefit loss (implying presumably that this action would never be taken) but increasing hours from 20 to 40 would result in earnings increases exceeding benefit losses and hence increases in net income (and therefore would be undertaken if the value of lost leisure were exceeded by the value of the additional income).

As for the reforms, an indexation of the SGA would have no effect on the monetary incentives or disincentives to leave the rolls because it would not affect income at the particular hours points we have chosen. However, the other three DI reforms significantly reduce the financial incentive to leave the rolls. Reducing the MTR would imply net income losses of 7 to 33 percent among workers who did not increase their work effort when exiting. In addition, individuals who, in the absence of the MTR reduction would have experienced a 48 percent increase in net income by working 40 hours off the rolls instead of 20 while on, would experience either much smaller increases ( 9 percent) or actual reductions (-1 percent) in net income. It is in this range that the MTR reduction has the largest impact on increasing income while on the rolls and thus reduces the incentives to exit. Extending the TWP by 12 months also reduces incentives to leave, because benefits are higher while on the rolls, but not by as large an amount as the MTR reductions. The effects of the earnings subsidies on exit incentives are rather small because the largest effect of those subsidies are in hours-worked ranges where the individual is already effectively off DI and working above the SGA. However, while the earnings subsidies do not greatly increase the leaving incentives for medium-wage workers, they at least do not reduce them significantly, unlike the DI reforms. 
Table 5 shows the percentage change in income from moving off the rolls (only earnings) to on the rolls (earnings plus benefits), and by either working the same amount or reducing work effort in the process. Under current law, a medium-wage recipient has large income gains of 52 or 26 percent, depending on whether he works part-time or full-time, if he goes onto DI (benefits are always received during the application period and the TWP). If the individual quits a part-time job to go onto the rolls and not work, income still increases by a large amount (39 percent) although not by as much as it would if he were to continue working while on the rolls; this would therefore seem to be a utility-maximizing move. However, going onto the rolls and reducing hours from 40 to 20 does not increase benefits by very much and therefore results in a net income loss (to be balanced against the increased value of leisure).

Except for the indexed SGA, which again has no effect, the DI reforms always increase the net income gain from going onto the rolls without changes in hours worked, often by large amounts (107 percent and 128 percent, for example, in the part-time range where the MTR reduction has its biggest effect). More important, while the incentives for quitting work entirely are unaffected by the reforms, since none of them alter benefits at zero hours, the income losses attendant upon reducing from full-time to part-time work are either greatly attenuated (for the TWP extension ) or reversed in sign (MTR reductions). In the latter case, therefore, net income can be increased by reducing hours and going onto the rolls, which again would appear to be a utility-maximizing choice.

The earnings subsidies have the opposite effect of the reforms if hours are unchanged, for they reduce the financial incentives to go onto the rolls, even though those net income gains are still positive (23 to 42 percent in the table). Net income gains from quitting work from a part-time job are also lower under the earnings subsidies, for those subsidies increase net income for workers off the rolls but not nonworkers. However, income losses from leaving a full-time job to work part-time on the rolls entail slightly smaller income penalties than under current law, but this is because net income losses and gains from changes in earnings in the phaseout range of an earnings subsidy are reduced even for those who 


\section{TABLE 5}

Percentage Change in Income from Entering DI under Current Law and Alternative Policies, Medium-Wage Recipient

\begin{tabular}{|c|c|c|c|c|}
\hline & \multicolumn{4}{|c|}{ Percentage Change in Income by Hours Worked ${ }^{\text {a }}$} \\
\hline & $20 \mathrm{hrs}$. & $40 \mathrm{hrs}$. & $20-40 \mathrm{hrs}$. & $20-40$ hrs. \\
\hline Current law & 52 & 26 & 39 & -24 \\
\hline Strict SGA & 19 & 10 & 39 & -40 \\
\hline \multicolumn{5}{|l|}{ DI Reforms } \\
\hline Index SGA & 52 & 26 & 39 & -24 \\
\hline $50 \%$ MTR over SGA & 128 & 46 & 39 & 14 \\
\hline $50 \%$ MTR over $\$ 85$ & 107 & 35 & 39 & 3 \\
\hline Extend TWP by 12 months & 85 & 42 & 39 & -8 \\
\hline \multicolumn{5}{|l|}{ Reforms outside DI } \\
\hline Earnings subsidy & 42 & 25 & 13 & -17 \\
\hline Earnings subsidy, non-DI & & & & \\
\hline recipients only & 37 & 23 & 13 & -20 \\
\hline
\end{tabular}

Note: These calculations compare total income over the five-year simulation period with and without DI benefits. The DI reforms affect only income opportunities on DI, but the non-DI reforms may affect income both on and off DI.

${ }^{a}$ The scenarios in the first two columns assume that the worker does not change hours of work when entering DI. In the last two columns, the worker is assumed to decrease hours worked when they enter the program, to the levels given. 
are off the rolls. In the 20-to-40 hours range for medium-wage workers, earnings are above SGA regardless and hence there is no additional benefit gain from going onto the rolls.

\section{CONCLUSIONS AND POLICY IMPLICATIONS}

As policy makers become more interested in the issue of increasing work incentives in the DI program, it will be even more important to understand the implications of changing financial inducements through changes in benefit formulas. Our discussion of the expected effects of such changes suggest that they are not as likely to be as effective as they first appear. Lying behind this potential ineffectiveness is a set of possible explanations that involve new entry into the programs as well as decreased exit. Changes in labor supply for these groups may offset the increase in labor supply among those who stay on the program. Unfortunately, the available empirical research on DI does not allow us to reach any conclusions on the magnitude of the response. But the direction of the different types of responses that result from financial inducements, both the intended increases in work effort and the unintended reductions, should be present. This leads us to urge caution in using financial inducements as a means of work-incentive reform in DI without further, concrete evidence of their effectiveness.

As an alternative, increasing work effort among the disabled may be achieved by the use of work and employment and training programs, and/or wage subsidies. Both of these policies have been advanced in recent years for the AFDC program, in part due to the perceived failure of within-program financial inducements. This shift also reflects a society-wide change in attitudes toward work among women with children, as it becomes increasingly the norm for such women to work rather than stay at home. A similar change in attitudes toward the disabled appears to have occurred, with many arguing that all recipients should work to the degree they can. However, the use of program-based financial inducements is still more favorably viewed in policy discussions of DI (and SSI) than in the AFDC and other welfare programs, which is not necessarily justified by the evidence. 
The attractiveness of an earnings subsidy such as the EITC is that it has the potential to increase work and earnings and to reduce the DI caseload at the same time. The philosophy behind the EITC and similar private sector earnings subsidy programs is diametrically opposite to that behind the use of within-program financial inducements to work more while on DI, for the latter has the potentially deleterious consequences of increasing the caseload and possibly reducing work effort, which we have discussed at length. These deleterious effects would not be present if financial inducements were offered only for off-DI (or both on- and off-DI) work. Policy discussions of disability programs might fruitfully turn to such programs, perhaps by investigating special private sector earnings subsidy programs for the disabled or modifications in the EITC to make more disabled individuals eligible for its benefits.

Major research gaps need to be filled to determine the effectiveness of any of these policies in increasing work effort and reducing caseloads in the DI program. Secondary analysis of existing data sets using econometric techniques must be pursued with more of an eye toward estimating wage and substitution elasticities, for example, although we recognize the difficulties in doing so. Alternatively, either large- or small-scale microsimulation models could be constructed and the effects of different work-incentive provisions could be predicted based upon a range of assumed responsiveness levels and elasticities; this would provide at least some indication of how large or small responsiveness needs to be for work-incentive provisions to have a genuine positive effect. Finally, direct experiments or demonstrations with the caseload would be helpful in obtaining estimates of the response to specific program initiatives, although we emphasize that program evaluations must also be designed to capture both the exit and entry effects of financial inducements. 


\section{APPENDIX}

TABLE A1

Earnings, Income, and Tax Rates in the DI Program under Current Law

\begin{tabular}{lrrrrr}
\hline & Earnings & Benefits & Net Income & MTR (\%) & ATR (\%) \\
\hline & & & & & \\
$\begin{array}{l}\text { Low-Wage Worker } \\
\quad \text { hours }\end{array}$ & $\$ 0$ & $\$ 27,498$ & $\$ 27,498$ & & \\
10 hours & $\$ 9,157$ & $\$ 27,498$ & $\$ 36,655$ & $0 \%$ & $0 \%$ \\
15 hours & $\$ 13,736$ & $\$ 27,498$ & $\$ 41,234$ & $0 \%$ & $0 \%$ \\
20 hours & $\$ 18,314$ & $\$ 16,153$ & $\$ 34,467$ & $248 \%$ & $62 \%$ \\
40 hours & $\$ 36,628$ & $\$ 10,323$ & $\$ 46,951$ & $32 \%$ & $47 \%$ \\
$\begin{array}{l}\text { Medium-Wage Worker } \\
0 \text { hours }\end{array}$ & & & & & \\
10 hours & $\$ 0$ & $\$ 43,444$ & $\$ 43,444$ & & \\
15 hours & $\$ 15,586$ & $\$ 43,444$ & $\$ 59,030$ & $0 \%$ & $0 \%$ \\
20 hours & $\$ 23,378$ & $\$ 16,310$ & $\$ 39,688$ & $348 \%$ & $116 \%$ \\
40 hours & $\$ 31,171$ & $\$ 16,310$ & $\$ 47,481$ & $0 \%$ & $87 \%$ \\
High-Wage Worker & $\$ 62,342$ & $\$ 16,310$ & $\$ 78,652$ & $0 \%$ & $44 \%$ \\
0 hours & & & & & \\
10 hours & & & & & \\
15 hours & $\$ 0$ & $\$ 55,984$ & $\$ 55,984$ & & \\
20 hours & $\$ 23,378$ & $\$ 21,018$ & $\$ 44,396$ & $150 \%$ & $150 \%$ \\
40 hours & $\$ 35,068$ & $\$ 21,018$ & $\$ 56,085$ & $0 \%$ & $100 \%$ \\
& $\$ 46,757$ & $\$ 21,018$ & $\$ 67,774$ & $0 \%$ & $75 \%$ \\
& $\$ 93,514$ & $\$ 21,018$ & $\$ 114,51$ & $0 \%$ & $37 \%$ \\
\hline
\end{tabular}

Note: The table presents results of simulation over a 57-month period starting in 1994. Earnings, income, and benefits are the PDV of the stream over the simulation period. 


\section{TABLE A2}

Earnings, Income, and Tax Rates in the DI Program under a Strict SGA Program

\begin{tabular}{|c|c|c|c|c|c|}
\hline & Earnings & Benefits & Net Income & $\operatorname{MTR}(\%)$ & $\operatorname{ATR}(\%)$ \\
\hline \multicolumn{6}{|c|}{ Low-Wage Worker } \\
\hline 0 hours & $\$ 0$ & $\$ 27,498$ & $\$ 27,498$ & & \\
\hline 10 hours & $\$ 9,157$ & $\$ 27,498$ & $\$ 36,655$ & $0 \%$ & $0 \%$ \\
\hline 15 hours & $\$ 13,736$ & $\$ 27,498$ & $\$ 41,234$ & $0 \%$ & $0 \%$ \\
\hline 20 hours & $\$ 18,314$ & $\$ 16,153$ & $\$ 34,467$ & $248 \%$ & $62 \%$ \\
\hline 40 hours & $\$ 36,628$ & $\$ 3,841$ & $\$ 40,469$ & $67 \%$ & $65 \%$ \\
\hline \multicolumn{6}{|c|}{ Medium-Wage Worker } \\
\hline 0 hours & $\$ 0$ & $\$ 43,444$ & $\$ 43,444$ & & \\
\hline 10 hours & $\$ 15,586$ & $\$ 43,444$ & $\$ 59,030$ & $0 \%$ & $0 \%$ \\
\hline 15 hours & $\$ 23,378$ & $\$ 6,069$ & $\$ 29,447$ & $480 \%$ & $160 \%$ \\
\hline 20 hours & $\$ 31,171$ & $\$ 6,069$ & $\$ 37,240$ & $0 \%$ & $120 \%$ \\
\hline 40 hours & $\$ 62,342$ & $\$ 6,069$ & $\$ 68,411$ & $0 \%$ & $60 \%$ \\
\hline \multicolumn{6}{|c|}{ High-Wage Worker } \\
\hline 0 hours & $\$ 0$ & $\$ 55,984$ & $\$ 55,984$ & & \\
\hline 10 hours & $\$ 23,378$ & $\$ 7,820$ & $\$ 31,199$ & $206 \%$ & $206 \%$ \\
\hline 15 hours & $\$ 35,068$ & $\$ 7,820$ & $\$ 42,888$ & $0 \%$ & $137 \%$ \\
\hline 20 hours & $\$ 46,757$ & $\$ 7,820$ & $\$ 54,577$ & $0 \%$ & $103 \%$ \\
\hline 40 hours & $\$ 93,514$ & $\$ 7,820$ & $\$ 101,334$ & $0 \%$ & $52 \%$ \\
\hline
\end{tabular}

Note: The table presents results of simulation over a 57-month period starting in 1994. Earnings, income, and benefits are the PDV of the stream over the simulation period. 
TABLE A3

Earnings, Income, and Tax Rates in the DI Program under a DI Reform: Index SGA

\begin{tabular}{lrrrrr}
\hline & Earnings & Benefits & Net Income & MTR (\%) & ATR (\%) \\
\hline $\begin{array}{l}\text { Low } \text {-Wage Worker } \\
\quad \text { hours }\end{array}$ & & & & & \\
10 hours & $\$ 0$ & $\$ 27,498$ & $\$ 27,498$ & & \\
15 hours & $\$ 9,157$ & $\$ 27,498$ & $\$ 36,655$ & $0 \%$ & $0 \%$ \\
20 hours & $\$ 13,736$ & $\$ 27,498$ & $\$ 41,234$ & $0 \%$ & $0 \%$ \\
40 hours & $\$ 18,314$ & $\$ 27,498$ & $\$ 45,812$ & $0 \%$ & $0 \%$ \\
& $\$ 36,628$ & $\$ 10,323$ & $\$ 46,951$ & $94 \%$ & $47 \%$ \\
$\begin{array}{l}\text { Medium-Wage Worker } \\
0 \text { hours }\end{array}$ & & & & & \\
10 hours & $\$ 0$ & $\$ 43,444$ & $\$ 43,444$ & & \\
15 hours & $\$ 15,586$ & $\$ 43,444$ & $\$ 59,030$ & $0 \%$ & $0 \%$ \\
20 hours & $\$ 23,378$ & $\$ 16,310$ & $\$ 39,688$ & $348 \%$ & $116 \%$ \\
40 hours & $\$ 31,171$ & $\$ 16,310$ & $\$ 47,481$ & $0 \%$ & $87 \%$ \\
& $\$ 62,342$ & $\$ 16,310$ & $\$ 78,652$ & $0 \%$ & $44 \%$ \\
High-Wage Worker & & & & & \\
0 hours & & & & & \\
10 hours & $\$ 0$ & $\$ 55,984$ & $\$ 55,984$ & & \\
15 hours & $\$ 23,378$ & $\$ 21,018$ & $\$ 44,396$ & $150 \%$ & $150 \%$ \\
20 hours & $\$ 35,068$ & $\$ 21,018$ & $\$ 56,085$ & $0 \%$ & $100 \%$ \\
40 hours & $\$ 46,757$ & $\$ 21,018$ & $\$ 67,774$ & $0 \%$ & $75 \%$ \\
\end{tabular}

Note: The table presents the results of simulation over a 57-month period starting in 1994. Earnings, income, and benefits are the PDV of the stream over the simulation period. 


\section{TABLE A4}

\section{Earnings, Income, and Tax Rates in the DI Program under a DI Reform: 50 Percent MTR over SGA}

\begin{tabular}{|c|c|c|c|c|c|}
\hline & Earnings & Benefits & Net Income & $\operatorname{MTR}(\%)$ & $\operatorname{ATR}(\%)$ \\
\hline \multicolumn{6}{|c|}{ Low-Wage Worker } \\
\hline 0 hours & $\$ 0$ & $\$ 27,498$ & $\$ 27,498$ & & \\
\hline 10 hours & $\$ 9,157$ & $\$ 27,498$ & $\$ 36,655$ & $0 \%$ & $0 \%$ \\
\hline 15 hours & $\$ 13,736$ & $\$ 27,498$ & $\$ 41,234$ & $0 \%$ & $0 \%$ \\
\hline 20 hours & $\$ 18,314$ & $\$ 27,498$ & $\$ 45,812$ & $0 \%$ & $0 \%$ \\
\hline 40 hours & $\$ 36,628$ & $\$ 21,911$ & $\$ 58,539$ & $31 \%$ & $15 \%$ \\
\hline \multicolumn{6}{|c|}{ Medium-Wage Worker } \\
\hline 0 hours & $\$ 0$ & $\$ 43,444$ & $\$ 43,444$ & & \\
\hline 10 hours & $\$ 15,586$ & $\$ 43,444$ & $\$ 59,030$ & $0 \%$ & $0 \%$ \\
\hline 15 hours & $\$ 23,378$ & $\$ 42,667$ & $\$ 66,045$ & $10 \%$ & $3 \%$ \\
\hline 20 hours & $\$ 31,171$ & $\$ 39,838$ & $\$ 71,009$ & $36 \%$ & $12 \%$ \\
\hline 40 hours & $\$ 62,342$ & $\$ 28,523$ & $\$ 90,865$ & $36 \%$ & $24 \%$ \\
\hline \multicolumn{6}{|c|}{ High-Wage Worker } \\
\hline 0 hours & $\$ 0$ & $\$ 55,984$ & $\$ 55,984$ & & \\
\hline 10 hours & $\$ 23,378$ & $\$ 55,206$ & $\$ 78,585$ & $3 \%$ & $3 \%$ \\
\hline 15 hours & $\$ 35,068$ & $\$ 50,963$ & $\$ 86,031$ & $36 \%$ & $14 \%$ \\
\hline 20 hours & $\$ 46,757$ & $\$ 46,720$ & $\$ 93,477$ & $36 \%$ & $20 \%$ \\
\hline 40 hours & $\$ 93,514$ & $\$ 29,747$ & $\$ 123,261$ & $36 \%$ & $28 \%$ \\
\hline
\end{tabular}

Note: The table presents the results of simulation over a 57-month period starting in 1994. Earnings, income, and benefits are the PDV of the stream over the simulation period. 


\section{TABLE A5}

\section{Earnings, Income, and Tax Rates in the DI Program under a DI Reform: 50 Percent MTR over $\$ 85$}

\begin{tabular}{lrrrrr}
\hline & Earnings & Benefits & Net Income & MTR (\%) & ATR (\%) \\
\hline $\begin{array}{l}\text { Low } \text {-Wage Worker } \\
\quad \text { hours }\end{array}$ & & & & & \\
10 hours & $\$ 0$ & $\$ 27,498$ & $\$ 27,498$ & & \\
15 hours & $\$ 9,157$ & $\$ 25,281$ & $\$ 34,438$ & $24 \%$ & $24 \%$ \\
20 hours & $\$ 13,736$ & $\$ 23,619$ & $\$ 37,355$ & $36 \%$ & $28 \%$ \\
40 hours & $\$ 18,314$ & $\$ 21,957$ & $\$ 40,271$ & $36 \%$ & $30 \%$ \\
& $\$ 36,628$ & $\$ 15,309$ & $\$ 51,937$ & $36 \%$ & $33 \%$ \\
$\begin{array}{l}\text { Medium-Wage Worker } \\
\text { 0 hours }\end{array}$ & & & & & \\
10 hours & $\$ 0$ & $\$ 43,444$ & $\$ 43,444$ & & \\
15 hours & $\$ 15,586$ & $\$ 38,893$ & $\$ 54,479$ & $29 \%$ & $29 \%$ \\
20 hours & $\$ 23,378$ & $\$ 36,065$ & $\$ 59,443$ & $36 \%$ & $32 \%$ \\
40 hours & $\$ 31,171$ & $\$ 33,236$ & $\$ 64,407$ & $36 \%$ & $33 \%$ \\
& $\$ 62,342$ & $\$ 21,921$ & $\$ 84,263$ & $36 \%$ & $35 \%$ \\
High-Wage Worker & & & & & \\
0 hours & & & & & \\
10 hours & $\$ 0$ & $\$ 55,984$ & $\$ 55,984$ & & \\
15 hours & $\$ 23,378$ & $\$ 48,604$ & $\$ 71,983$ & $32 \%$ & $32 \%$ \\
20 hours & $\$ 35,068$ & $\$ 44,361$ & $\$ 79,429$ & $36 \%$ & $33 \%$ \\
40 hours & $\$ 46,757$ & $\$ 40,118$ & $\$ 86,875$ & $36 \%$ & $34 \%$ \\
\hline
\end{tabular}

Note: The table presents the results of simulation over a 57-month period starting in 1994. Earnings, income, and benefits are the PDV of the stream over the simulation period. 
TABLE A6

Earnings, Income, and Tax Rates in the DI Program under a DI Reform: Extend TWP

\begin{tabular}{lrrrrr}
\hline & Earnings & Benefits & Net Income & MTR (\%) & ATR (\%) \\
\hline & & & & & \\
$\begin{array}{l}\text { Low } \text { Wage Worker } \\
\quad \text { hours }\end{array}$ & $\$ 0$ & $\$ 27,498$ & $\$ 27,498$ & & \\
10 hours & $\$ 9,157$ & $\$ 27,498$ & $\$ 36,655$ & $0 \%$ & $0 \%$ \\
15 hours & $\$ 13,736$ & $\$ 27,498$ & $\$ 41,234$ & $0 \%$ & $0 \%$ \\
20 hours & $\$ 18,314$ & $\$ 16,678$ & $\$ 34,992$ & $236 \%$ & $59 \%$ \\
40 hours & $\$ 36,628$ & $\$ 16,678$ & $\$ 53,306$ & $0 \%$ & $30 \%$ \\
& & & & & \\
Medium-Wage Worker & $\$ 0$ & $\$ 43,444$ & $\$ 43,444$ & & \\
0 hours & $\$ 15,586$ & $\$ 43,444$ & $\$ 59,030$ & $0 \%$ & $0 \%$ \\
10 hours & $\$ 23,378$ & $\$ 26,349$ & $\$ 49,728$ & $219 \%$ & $73 \%$ \\
15 hours & $\$ 31,171$ & $\$ 26,349$ & $\$ 57,520$ & $0 \%$ & $55 \%$ \\
20 hours & $\$ 62,342$ & $\$ 26,349$ & $\$ 88,692$ & $0 \%$ & $27 \%$ \\
40 hours & & & & & \\
High-Wage Worker & $\$ 0$ & $\$ 55,984$ & $\$ 55,984$ & & \\
0 hours & $\$ 23,378$ & $\$ 33,955$ & $\$ 57,333$ & $94 \%$ & $94 \%$ \\
10 hours & $\$ 35,068$ & $\$ 33,955$ & $\$ 69,022$ & $0 \%$ & $63 \%$ \\
15 hours & $\$ 46,757$ & $\$ 33,955$ & $\$ 80,711$ & $0 \%$ & $47 \%$ \\
20 hours & $\$ 93,514$ & $\$ 33,955$ & $\$ 127,468$ & $0 \%$ & $24 \%$ \\
\hline 0 hours & & & & \\
\hline
\end{tabular}

Note: The table presents the results of simulation over a 57-month period starting in 1994. Earnings, income, and benefits are the PDV of the stream over the simulation period. 
TABLE A7

Earnings, Income, and Tax Rates in the DI Program under a Non-DI Reform: Earnings Subsidy for All Disabled Workers

\begin{tabular}{|c|c|c|c|c|c|c|}
\hline & Earnings & Benefits & $\begin{array}{l}\text { Earnings } \\
\text { Subsidy }\end{array}$ & $\begin{array}{c}\text { Net } \\
\text { Income }\end{array}$ & $\operatorname{MTR}(\%)$ & $\operatorname{ATR}(\%)$ \\
\hline \multicolumn{7}{|c|}{ Low-Wage Worker } \\
\hline 0 hours & $\$ 0$ & $\$ 27,498$ & $\$ 0$ & $\$ 27,498$ & & \\
\hline 10 hours & $\$ 9,157$ & $\$ 27,498$ & $\$ 3,113$ & $\$ 39,769$ & $-34 \%$ & $-34 \%$ \\
\hline 15 hours & $\$ 13,736$ & $\$ 15,628$ & $\$ 4,670$ & $\$ 34,033$ & $225 \%$ & $52 \%$ \\
\hline 20 hours & $\$ 18,314$ & $\$ 10,323$ & $\$ 6,227$ & $\$ 34,864$ & $82 \%$ & $60 \%$ \\
\hline 40 hours & $\$ 36,628$ & $\$ 10,323$ & $\$ 7,220$ & $\$ 54,172$ & $-5 \%$ & $27 \%$ \\
\hline \multicolumn{7}{|c|}{ Medium-Wage Worker } \\
\hline 0 hours & $\$ 0$ & $\$ 43,444$ & $\$ 0$ & $\$ 43,444$ & & \\
\hline 10 hours & $\$ 15,586$ & $\$ 16,310$ & $\$ 5,299$ & $\$ 37,195$ & $140 \%$ & $140 \%$ \\
\hline 15 hours & $\$ 23,378$ & $\$ 16,310$ & $\$ 7,220$ & $\$ 46,909$ & $-25 \%$ & $85 \%$ \\
\hline 20 hours & $\$ 31,171$ & $\$ 16,310$ & $\$ 7,220$ & $\$ 54,701$ & $0 \%$ & $64 \%$ \\
\hline 40 hours & $\$ 62,342$ & $\$ 16,310$ & $\$ 3,479$ & $\$ 82,132$ & $12 \%$ & $38 \%$ \\
\hline \multicolumn{7}{|c|}{ High-Wage Worker } \\
\hline 0 hours & $\$ 0$ & $\$ 55,984$ & $\$ 0$ & $\$ 55,984$ & & \\
\hline 10 hours & $\$ 23,378$ & $\$ 21,018$ & $\$ 7,220$ & $\$ 51,616$ & $119 \%$ & $119 \%$ \\
\hline 15 hours & $\$ 35,068$ & $\$ 21,018$ & $\$ 7,220$ & $\$ 63,305$ & $0 \%$ & $79 \%$ \\
\hline 20 hours & $\$ 46,757$ & $\$ 21,018$ & $\$ 5,970$ & $\$ 73,744$ & $11 \%$ & $62 \%$ \\
\hline 40 hours & $\$ 93,514$ & $\$ 21,018$ & $\$ 0$ & $\$ 114,531$ & $13 \%$ & $37 \%$ \\
\hline
\end{tabular}

Note: The table presents the results of simulation over a 57-month period starting in 1994. Earnings, income, and benefits are the PDV of the stream over the simulation period. 


\section{TABLE A8}

\section{Earnings, Income, and Tax Rates in the DI Program under a Non-DI Reform: Earnings Subsidy for Non-DI Recipients}

\begin{tabular}{|c|c|c|c|c|c|c|}
\hline & Earnings & Benefits & $\begin{array}{l}\text { Earnings } \\
\text { Subsidy }\end{array}$ & $\begin{array}{c}\text { Net } \\
\text { Income }\end{array}$ & $\operatorname{MTR}(\%)$ & $\operatorname{ATR}(\%)$ \\
\hline \multicolumn{7}{|c|}{ Low-Wage Worker } \\
\hline 0 hours & $\$ 0$ & $\$ 27,498$ & $\$ 0$ & $\$ 27,498$ & & \\
\hline 10 hours & $\$ 9,157$ & $\$ 27,498$ & $\$ 0$ & $\$ 36,655$ & $0 \%$ & $0 \%$ \\
\hline 15 hours & $\$ 13,736$ & $\$ 27,498$ & $\$ 0$ & $\$ 41,234$ & $0 \%$ & $0 \%$ \\
\hline 20 hours & $\$ 18,314$ & $\$ 16,153$ & $\$ 2,986$ & $\$ 37,453$ & $183 \%$ & $46 \%$ \\
\hline 40 hours & $\$ 36,628$ & $\$ 10,323$ & $\$ 5,242$ & $\$ 52,193$ & $20 \%$ & $33 \%$ \\
\hline \multicolumn{7}{|c|}{ Medium-Wage Worker } \\
\hline 0 hours & $\$ 0$ & $\$ 43,444$ & $\$ 0$ & $\$ 43,444$ & & \\
\hline 10 hours & $\$ 15,586$ & $\$ 43,444$ & $\$ 0$ & $\$ 59,030$ & $0 \%$ & $0 \%$ \\
\hline 15 hours & $\$ 23,378$ & $\$ 16,310$ & $\$ 5,242$ & $\$ 44,930$ & $281 \%$ & $94 \%$ \\
\hline 20 hours & $\$ 31,171$ & $\$ 16,310$ & $\$ 5,242$ & $\$ 52,723$ & $0 \%$ & $70 \%$ \\
\hline 40 hours & $\$ 62,342$ & $\$ 16,310$ & $\$ 2,526$ & $\$ 81,178$ & $9 \%$ & $39 \%$ \\
\hline \multicolumn{7}{|c|}{ High-Wage Worker } \\
\hline 0 hours & $\$ 0$ & $\$ 55,984$ & $\$ 0$ & $\$ 55,984$ & & \\
\hline 10 hours & $\$ 23,378$ & $\$ 21,018$ & $\$ 5,242$ & $\$ 49,638$ & $127 \%$ & $127 \%$ \\
\hline 15 hours & $\$ 35,068$ & $\$ 21,018$ & $\$ 5,242$ & $\$ 61,327$ & $0 \%$ & $85 \%$ \\
\hline 20 hours & $\$ 46,757$ & $\$ 21,018$ & $\$ 4,334$ & $\$ 72,109$ & $8 \%$ & $66 \%$ \\
\hline 40 hours & $\$ 93,514$ & $\$ 21,018$ & $\$ 0$ & $\$ 114,531$ & $9 \%$ & $37 \%$ \\
\hline
\end{tabular}

Note: The table presents the results of simulation over a 57-month period starting in 1994. Earnings, income, and benefits are the PDV of the stream over the simulation period. 


\section{References}

Bound, John. 1989. "The Health and Earnings of Rejected Disability Insurance Applicants." American Economic Review 79(3) (June): 482-503.

Bound, John. 1991. "The Health and Earnings of Rejected Disability Insurance Applicants: Reply." American Economic Review (December): 1427-34.

Burkhauser, R., and M. Daly. 1996. "Employment and Economic Well-Being Following the Onset of a Disability: The Role for Public Policy." In Disability, Work, and Cash Benefits, ed. J. Mashaw, V. Reno, R. Burkhauser, and M. Berkowitz. Kalamazoo, Mich.: W. E. Upjohn Institute.

Eissa, Nada, and Jeffrey Liebman. 1996. "Labor Supply Response to the Earned Income Tax Credit." Quarterly Journal of Economics 111 (May): 605-37.

Eissa, Nada, and Hilary Hoynes. 1997. "The Earned Income Tax Credit and Labor Supply: Married Couples." Mimeo, University of California.

Halpern, J., and J. Hausman. 1986. "Choice under Uncertainty: A Model of Applications for the SSDI Program.” Journal of Public Economics 3: 131-61.

Haveman, Robert, and Barbara Wolfe. 1984. "The Decline in Male Labor Force Participation: Comment." Journal of Political Economy 92(3): 532-41.

Hoynes, Hilary, and Robert Moffitt. 1996. "The Effectiveness of Financial Work Incentives in SSDI and SSI: Lessons from Other Transfer Programs.” In Disability, Work, and Cash Benefits, ed. J. Mashaw, V. Reno, R. Burkhauser, and M. Berkowitz. Kalamazoo, Mich.: W. E. Upjohn Institute.

Leonard, Jonathan. 1986. "Labor Supply Incentives and Disincentives for Disabled Persons." In Disability and the Labor Market, ed. M. Berkowitz and M. A. Hill. Ithaca, N.Y.: ILR Press.

Levy, Frank. 1979. "The Labor Supply of Female Heads, or AFDC Work Incentives Don't Work Too Well." Journal of Human Resources 14 (Winter): 76-97.

Moffitt, Robert. 1992. "Incentive Effects of the U.S. Welfare System: A Review." Journal of Economic Literature 30 (March): 1-61.

National Academy of Social Insurance. 1994. Preliminary Status Report of the Disability Policy Panel. March.

Parsons, Donald. 1980a. "The Decline in Male Labor Force Participation.” Journal of Political Economy 88(1): 117-34.

Parsons, Donald. 1980b. "Racial Trend in Male Labor Force Participation.” American Economic Review 70: 911-20.

Parsons, Donald. 1984. "Disability Insurance and Male Labor Force Participation: A Response to Haveman and Wolfe." Journal of Political Economy 92(3): 542-49. 
Parsons, Donald. 1991. "The Health and Earnings of Rejected Disability Insurance Applicants: Comment.” American Economic Review (December 1991): 1419-26.

Social Security Administration, U.S. Department of Health and Human Services. 1992. Annual Statistical Supplement to the Social Security Bulletin Washington, D.C.: U.S. Government Printing Office.

Social Security Administration, U.S. Department of Health and Human Services. 1995. Annual Statistical Supplement to the Social Security Bulletin. Washington, D.C.: U.S. Government Printing Office.

U.S. House of Representatives, Committee on Ways and Means. 1994. Green Book: Background Material and Data on Programs within the Jurisdiction of the Committee on Ways and Means. Washington, D.C.: U.S. Government Printing Office.

U.S. House of Representatives, Committee on Ways and Means. 1996. Green Book: Background Material and Data on Programs within the Jurisdiction of the Committee on Ways and Means. Washington, D.C.: U.S. Government Printing Office. 